\title{
Varicose veins in a Finnish population aged 40-60
}

\author{
Jari Laurikka, Tero Sisto, Ossi Auvinen, Matti Tarkka, Esa Läärä, Matti Hakama
}

\begin{abstract}
Study objective-To assess the prevalence and the extent of treatment of varicose veins in a Finnish population.

Design-A prevalence study in a defined cohort was performed by using a mailed questionnaire. The method's validity was tested in a random sample of 166 individuals who were studied clinically.

Subjects-In 1989 a questionnaire was mailed to every resident born in 1929, 1939, and 1949 who was living in Tampere, the second largest town in Finland. The eligible population comprised 3284 men and 3590 women. Measurements and main results-The response rate was $75 \%$ in men and $86 \%$ in women. Both the sensitivity and specificity of the self assessed diagnosis were 0.92 . The life time prevalence of varicose veins was $18 \%$ for men and $32 \%$ for women, with an increasing prevalence in relation to age. Twenty five per cent of the men and $41 \%$ of the women who reported varicose veins had received treatment.

Conclusions-Self reporting of varicose veins by mailed questionnaire was a relatively valid method. The prevalence of varicose veins was high in the population studied, and the disease is more common in women than men. Moreover, the prevalence increased with age. The results are comparable with other western populations. Preventive methods are needed because treatment alone seems to be inadequate in the control of varicose veins.
\end{abstract}

f Epidemiol Community Health 1993; 47: 355-357

Departments of

Surgery and Public

Health, University

Hospital of Tampere,

Sf-33520 Tampere,

Finland.

J Laurikka

T Sisto

O Auvinen

M Tarkka

Department of Public

Health, University of

Tampere, Finland

M Hakama

Department of

Applied Mathematics

and Statistics,

University of Oulu,

Finland

Esa Läärä

Correspondence to:

Dr J Laurikka

Department of Surgery

Accepted for publication May 1993
Because there are no extensive studies on the prevalence of varicose veins in Finland and in other Nordic countries, knowledge of their occurrence and determining factors is lacking. We therefore undertook a cross sectional study of the occurrence of varicose veins in a Finnish population.

\section{Methods}

All people born in 1929, 1939, and 1949 and resident in Tampere, a city in southern Finland with 171307 inhabitants (in 1989), were identified from the National Population Registry in 1989, and their addresses were received from the same registry. These 3284 men and 3590 women formed the study population. In September 1989 they were sent a questionnaire in which they were asked to indicate if they had ever had varicose veins. Varicose veins were defined as "clearly visible, dilated, tortuous, and possibly prominent subcutaneous veins of the lower extremities" according to a definition used in other epidemiological surveys of varicose veins. ${ }^{7}{ }^{12-14}$ By definition, telangiectasia were not taken as varicose veins. The severity of the varicose veins was not graded further. The subjects were also asked about any surgery or sclerotherapy treatment for varicose veins. An identical questionnaire was mailed one to two months later to those who had not responded to the first questionnaire.

The prevalence of varicose veins was defined as the proportion of subjects who reported having had varicose veins during their life time in relation to all respondents (lifetime prevalence). Unless otherwise stated, the reported proportions are the actual observed prevalences based on self reporting. Adjustments for non-response and misclassification were also attempted. The adjustment for the bias caused by non-response was approximated by extrapolating linearly the prevalence of the non-responding group from the proportional changes in the prevalences among the subgroups who responded to the first and reminder questionnaires. The effect of misclassification on the prevalence of varicose veins was adjusted for by using the formula: ${ }^{15}$

$$
\mathrm{P}^{\mathrm{a}}=[\mathrm{P}-(1-\mathrm{Sp})] /[\mathrm{Se}-(1-\mathrm{Sp})]
$$

where $P^{a}$ is the adjusted prevalence, $P$ observed prevalence based on self reporting, and $\mathrm{Sp}$ and $\mathrm{Se}$ the observed values for specificity and sensitivity of the self assessed diagnosis.

The accuracy of self assessed diagnosis was estimated in a blinded study of 166 randomly sampled respondents born in 1939. The self evaluations were compared with the clinical 
Table I Self assessed diagnosis of varicose veins (VV) compared with the assessment by the surgeon

\begin{tabular}{|c|c|c|c|c|c|c|}
\hline \multirow{3}{*}{$\begin{array}{l}\text { Self assessed } \\
\text { diagnosis }\end{array}$} & \multicolumn{6}{|c|}{ Diagnosis by the surgeon } \\
\hline & \multicolumn{3}{|c|}{ No of men } & \multicolumn{3}{|c|}{ No of women } \\
\hline & $\overline{V V}$ & No. VV & All & $V V$ & No. $V V$ & All \\
\hline $\begin{array}{l}\mathrm{VV} \\
\text { No. VV } \\
\text { All }\end{array}$ & $\begin{array}{r}14 \\
1 \\
15\end{array}$ & $\begin{array}{r}44 \\
54 \\
58\end{array}$ & $\begin{array}{l}18 \\
55 \\
73\end{array}$ & $\begin{array}{r}36 \\
3 \\
39\end{array}$ & $\begin{array}{r}5 \\
49 \\
54\end{array}$ & $\begin{array}{l}41 \\
52 \\
93\end{array}$ \\
\hline
\end{tabular}

evaluation by a surgeon (JL). The results are presented in table I. The specificity $(95 \%$ confidence interval $(\mathrm{CI}))$ of the self assessed diagnosis was $0.93(0.83,0.98)$ in men and $0.91(0.80,0.97)$ in women. Correspondingly, the sensitivity was $0.93(0.68,1.0)$ in men and $0.92(0.79,0.98)$ in women. The $95 \% \mathrm{CI}$ for the observed sensitivity and specificity values were calculated by the "exact" binomial method using the computer program CIA. ${ }^{16}$

\section{Results}

Altogether 2467 men and 3101 women in the study population filled in and returned the questionnaire. Thus, the response rates were $75 \%$ in men and $86 \%$ in the women (table II). Eighty eight per cent of the participating men and $93 \%$ of the participating women responded to the first questionnaire.

Varicose veins were reported more often by women than by men. Altogether 2013 men (82\%) and 1808 women $(58 \%)$ reported that they had never had varicose veins or were uncertain of having had them. The prevalence of self assessed varicose veins increased with age in both genders, as shown in table III. Unilateral varicose veins were slightly more common $(11 \%$ in men and $23 \%$ in women) than bilateral varicose veins $(6 \%$ in men and $17 \%$ in women) and the finding was consistent in the three cohorts.

Treatment for varicosis was also more common in women. The proportions with a history of surgery or sclerotherapy treatment for varicose veins increased with age from 2 to $7 \%$ in men and 9 to $26 \%$ in women. The proportions of individuals who reported a history of treatment for varicosis out of all those reporting varicose veins were $25 \%$ in men and $41 \%$ in women (table IV). In consequence, the actual point prevalence proportions of self reported varicose veins at the time of the study in men were 11,20 , and $20 \%$ in the cohorts aged 40,50, and 60 years respectively. In the women the corresponding prevalences were 27,39 , and $47 \%$.
Table II Response rate in the three birth cohorts in relation to gender

\begin{tabular}{llll}
\hline Age $(y)$ & Gender & Total population & Participation rate (\%) \\
\hline 40 & Male & 1499 & 70.5 \\
& Female & 1489 & 85.2 \\
50 & Male & 980 & 76.5 \\
& Female & 1060 & 88.0 \\
60 & Male & 805 & 82.0 \\
Total & Female & 1041 & 86.4 \\
\hline
\end{tabular}

Table III Self assessment of ever having varicose veins (VV); proportions of individuals (\%) by age and gender

\begin{tabular}{|c|c|c|c|c|c|c|c|c|}
\hline \multirow[b]{3}{*}{ Self assessment } & \multicolumn{8}{|c|}{ Gender and age $(y)$} \\
\hline & \multicolumn{4}{|l|}{ Male } & \multicolumn{4}{|l|}{ Female } \\
\hline & 40 & 50 & 60 & All & 40 & 50 & 60 & All \\
\hline $\begin{array}{l}\text { Certain of having VV } \\
\text { Uncertain of VV } \\
\text { Definitely no VV } \\
\text { Total } \\
\text { (No participating) }\end{array}$ & $\begin{array}{c}12 \\
3 \\
85 \\
100 \\
(1057)\end{array}$ & $\begin{array}{c}24 \\
2 \\
74 \\
100 \\
(750)\end{array}$ & $\begin{array}{c}23 \\
3 \\
74 \\
100 \\
(660)\end{array}$ & $\begin{array}{c}18 \\
3 \\
79 \\
100 \\
(2467)\end{array}$ & $\begin{array}{c}31 \\
5 \\
64 \\
100 \\
(1268)\end{array}$ & $\begin{array}{c}45 \\
4 \\
51 \\
100 \\
(933)\end{array}$ & $\begin{array}{c}54 \\
5 \\
41 \\
100 \\
(900)\end{array}$ & $\begin{array}{r}42 \\
5 \\
53 \\
100 \\
(3101)\end{array}$ \\
\hline
\end{tabular}

The observed prevalences of varicose veins in the subpopulations who responded to the first and the repeated questionnaires differed only in men: the prevalences were substantially higher in those

Table IV Number (\%) of individuals who reported having varicose veins (VV) ever and at time of the study and the reported history of treatment for varicose veins

\begin{tabular}{lllll}
\hline & \multicolumn{2}{l}{$\begin{array}{l}\text { Male } \\
(n=2467)\end{array}$} & \multicolumn{2}{l}{$\begin{array}{l}\text { Female } \\
(n=3101)\end{array}$} \\
\cline { 2 - 3 } & No & $(\%)$ & No & $(\%)$ \\
\hline $\begin{array}{l}\text { Reporting VV ever } \\
\begin{array}{l}\text { Reporting VV at time } \\
\text { of the study }\end{array}\end{array}$ & 454 & $(18)$ & 1293 & $(42)$ \\
Reporting treatment & 397 & $(16)$ & 1126 & $(38)$ \\
\hline
\end{tabular}

who responded to the first questionnaire $(13 v 7$, $24 v 17 \%$, and $24 v 7 \%$ in the 40,50 , and 60 year olds, respectively). In the women the prevalences in the corresponding ages were (the first $v$ the second questionnaire) $31 v 28 \%, 45 v 50 \%$, and $55 v 52 \%$.

The observed original prevalences were adjusted for the effects of non-response. Furthermore, the observed prevalences were adjusted for the effects of misclassification by using the estimated specificity and sensitivity (Table V).

Table V Observed and adjusted prevalences (\%) of varicose veins

\begin{tabular}{|c|c|c|c|c|c|c|}
\hline & \multicolumn{6}{|c|}{ Gender and age $(y)$} \\
\hline & \multicolumn{3}{|c|}{ Male } & \multicolumn{3}{|c|}{ Female } \\
\hline & $\overline{40}$ & 50 & 60 & 40 & 50 & 60 \\
\hline $\begin{array}{l}\text { Observed prevalence } \\
\text { Adjusted prevalence } \\
\text { Adjusted prevalence }\end{array}$ & $\begin{array}{r}12 \\
9 \\
3\end{array}$ & $\begin{array}{l}24 \\
21 \\
16\end{array}$ & $\begin{array}{l}23 \\
20 \\
15\end{array}$ & $\begin{array}{l}31 \\
30 \\
25\end{array}$ & $\begin{array}{l}45 \\
46 \\
45\end{array}$ & $\begin{array}{l}54 \\
54 \\
54\end{array}$ \\
\hline
\end{tabular}

\section{Discussion}

Varicose veins are fairly common in Finland (which has a population of five million). According to original data from the National Agency for Welfare and Health, approximately 11000 varicose vein operations are performed each year in general hospitals in Finland. No epidemiological data, however, on varicose veins in Finland have been published to date.

The study population was from an urban area in the south of Finland with a fairly homogenous ethnic composition. No published data exist about the potential differences in the prevalences of varicose veins in urban and rural parts of Finland.

The response rate in our study was high, especially in women. The occurrence of varicose veins in men seemed to be associated with response to the questionnaire. The questionnaire method used in this study proved to be fairly accurate in measuring the prevalence of clinically important varicose veins in a moderately large study population. The estimated specificity and sensitivity of the questionnaire method in identifying subjects with varicose veins were reasonably high. In some previous studies the accuracy of self reporting of chronic conditions (including varicose veins) has typically been lower. ${ }^{17} \mathrm{~A}$ similar specificity $(85-95 \%)$ but a lower sensitivity $(47-67 \%)$ was reported in an interview study in 
Israel. ${ }^{6}$ In the present study, the adjustments for the effects of both selection (as a result of nonresponse) and misclassification yielded somewhat smaller prevalences than those based on self reporting among those who responded.

The prevalence of varicose veins was also comparable with the findings obtained from studies on other white populations. Apart from chance, the observed differences in the prevalences between this study and other studies may, for example, be due to differences in diagnostic criteria. In this study, the prevalence of varicose veins in women was 2.3 times that in men, and the finding was consistent with other reports showing prevalence ratios of $2 \cdot 0,{ }^{4} 2 \cdot 8,{ }^{6}$ and $1 \cdot 3 .{ }^{8} 10$

In the study population the prevalence was lowest in the youngest cohort in both sexes. However, varicose veins may develop at any age after adolescence. The results of the Framingham Study from a population with the minimum age of 40 years have indicated that the incidence of varicose veins varies by age with the highest incidence rates being found in men aged 70-79 and in middle aged (40-49 years) women. ${ }^{10}$ Although our study did not include people older than 60 years, these results, especially for women, agree with those obtained in the Framingham Study.

Treatment for varicose veins was common in the older people but was infrequent among younger men. The proportion of treated cases clearly increased with age. The reasons for treatment or abstaining from treatment were not evaluated. Similarly, the pathophysiological extent of the varicose disease was unknown. Therefore, individuals with no treatment may have had the least severe form of varicosis. A history of previous treatment for varicose veins had no substantial effect on the actual occurrence of all forms of varicose veins at the time of the study, even though in Tampere, according to the hospital discharge records, the treatment rate for varicosis has exceeded the rate observed in the rest of the country.

A relatively high proportion (50 to $80 \%$ ) of people had not been given any treatment for their varicose veins. In spite of this, the alleviating effects of the treatment on the symptoms or signs of varicosis could still have been considerable in many of those treated individuals but it was not possible to evaluate this in our survey.

In conclusion, varicose veins are common in middle aged Finnish people and were reported especially often by women. When compared with other nationalities, varicose veins affect Finns to a similar extent. Curative treatment was possible in a minority of individuals with varicosis. Therefore, preventive measures could be beneficial and the main risk factors of varicosis need to be studied further.

1 Editorial. Lancet 1884 ; i: $808-9$

King ESJ. The genesis of varicose veins. Aust ${ }^{\prime} Z \mathcal{F}$ Surg 1950; 20: 126-33.

Cotton L. Varicose veins: gross anatomy and development. Br F Surg 1969; 48: 589-98.

4 Coon WW, Willis PW, Keller JB: Venous thromboembolism and other venous diseases in the Tecumseh Community Health Study. Circulation 1973; 48: 839-46.

5 Bobek K, Cajzl L, Cepelak V, Slaisova V, Opatzny K, Barcal $\mathrm{R}$ : Etude de la fréquence des maladies phlebologiques et de l'influence de quelques facteurs étiologiques. Phlebologie 1966; 19: 217-33.

6 Abramson JH, Hopp C, Epstein LM. The epidemiology of varicose veins. A survey in western Jerusalem. $\mathcal{F}$ Epidemiol varicose veins. A survey in western
Community Health 1981; 35: 213-7.

7 Beaglehole R, Prior IAM, Salmond CE, Davidson F. Varicose veins in the South Pacific. Int F Epidemiol 1975; 4: 295-9.

8 Maffei FHA, Magaldi C, Pinho SZ, Lastoria S, Pinho W, Yoshida WB, Rollo H: Varicose veins and chronic venous insufficiency in Brazil: prevalence among 1755 inhabitants of a country town. Int $\mathcal{f}$ Epidemiol 1986; 15: 210-17.

9 Ducimetiere P, Richard JL, Pequignot G, Wamet JM. Varicose veins: a risk factor for atherosclerotic disease in middle-aged men? Int $f$ Epidemiol 1981; 10: 329-35.

10 Brand FN, Dannenberg AL, Abbott RD, Kannell WB. The epidemiology of varicose veins: the Framingham study. $\mathrm{Am}$ F Prev Med 1988; 4: 96-101.

11 Widmer LK and Wandeler JM: Leg complaints and peripheral venous disorders. In: Widmer LK, ed. Peripheral venous disorders, Bern: Hans Huber Publishers, 1978: venous 34 . 2 .

12 Arnoldi CC. The etiology of primary varicose veins. Dan Med Bull 1957; 4: 102-7.

13 Malhotra SL. An epidemiological study of varicose veins in Indian railroad workers from the south and north of India, Indian railroad workers from the south and north of India, with special attention to the causation and pre
varicose veins. Int $\mathcal{F}$ Epidemiol $1972 ; 1: 177-83$.

14 Stanhope JM. Varicose veins in a population of lowland New Guinea. Int $f$ Epidemiol $1975 ; 4: 221-5$.

15 Gastwirth JL. The statistical precision of medical screening procedures: Application to polygraph and AIDS antibodies test data. Statistical Science 1987; 2: 213-38

16 Gardner MJ, Altman DG: Calculating confidence intervals for proportions and their differences. In: Gardner MJ, Altman DG, eds. Statistics with confidence, London: British Medical Journal, 1989: 28-33

17 Cannell CF. A summary of studies of interviewing methodology. In: Data evaluation and methods research. Rockville: US Department of Health, Education and Welfare, 1977: 11. (Vital and health statistics; Series 2, no 